\title{
Decision-making for Cross-Laminated Timber Modular Construction Logistics Using Discrete Event Simulation
}

\author{
Bahar Abiri $^{1 *}$, Joseph Louis ${ }^{2}$, and Mariapaola Riggio ${ }^{3}$ \\ ${ }^{1}$ MSc Student, Department of Civil Engineering, Oregon State University \\ ${ }^{2}$ Assistant Professor, Department of Civil Engineering, Oregon State University \\ ${ }^{3}$ Assistant Professor, Department of Wood Science and Engineering, Oregon State University \\ ${ }^{*}$ Corresponding author's e-mail: abirib@oregonstate.edu
}

\begin{abstract}
Modular construction is being touted as one solution to address project delays and cost overruns in the construction industry. Modular construction is a delivery method wherein building components are prefabricated off-site and then transported to the job site for assembly. Thus, prefabrication is a significant element of modular construction that enables work to happen in parallel to accelerate project schedules, enhance safety, and reduce physical work on-site. Timber is becoming a primary material for prefabricating elements since wood is a renewable material, possesses high strength-weight ratio, and sequesters carbon. The use of wood in the form of cross-laminated timber (CLT) introduces new opportunities but also logistical issues in the supply chain from forest to the manufacturing facility to the construction site. Depending on the type of CLT and the level of modularity (i.e., 2D elements or volumetric), major constraints in this process have been identified including (1) fluctuation in the supply of raw wood to manufacturing facilities, (2) limitations in the capacity to create CLT panels, (3) shipping limitations based on allowable loads, and (4) crane availability for assembly of panels on the site. This paper explores the use of simulation models to study the effect of these logistical constraints in modular construction using prefabricated CLT on the total time and hence cost of projects. Specifically, discrete event simulation (DES) will be used to model CLT logistics to identify bottlenecks and provide sensitivity analyses of variables such as lumber supply, travel times, and manufacturing plant capacity on project cost and time. A case study of modular multi-story building construction is examined to showcase the utility of the developed simulation framework. It is expected that simulating modular CLT logistics will enable the identification of optimal strategies towards their successful implementation.
\end{abstract}

\section{KEYWORDS}

Modular construction; Discrete-event simulation; Cross-laminated timber; Prefabrication

\section{INTRODUCTION}

Advanced, highly performing, large scale timber buildings have been designed and constructed in the last two decades featuring innovative solutions and, typically, project-specific details individually developed and optimised for each building. While this is typical when innovation is created and introduced in a sector, standardisation is a process that can substantially contribute to further development and diffusion of a given solution and construction system (Blind, 2013). 
Modular construction is one solution to address project delays and cost overruns in the construction industry. Modular construction is a delivery method wherein building components are prefabricated off-site and then transported to the job site for assembly. Thus, prefabrication is a significant element of modular construction that enables work to happen in parallel to accelerate project schedules, enhance safety, and reduce physical work on-site. Timber is becoming a primary material for prefabricating elements since wood is a renewable material, possesses high strength-weight ratio, and sequesters carbon. The use of wood in the form of cross-laminated timber (CLT) introduces new opportunities but also logistical issues in the supply chain from forest to the manufacturing facility to the construction site.

This paper explores the use of simulation models to study the effect of these logistical constraints in modular construction using prefabricated CLT on the total time and cost of projects. Specifically, discrete event simulation (DES) will be used to model CLT logistics to identify bottlenecks and provide sensitivity analyses of variables such as lumber supply, travel times, and manufacturing plant capacity on project cost and time.

\section{BACKGROUND}

Construction processes can be broadly divided into onsite and off-site operations. Any construction process done in the place where the final product is to remain is denominated as onsite construction. While there is typically not much opportunity to improve productivities in onsite construction due to space and resource constraints, such opportunities exist when components are prefabricated off-site (Eastman and Sacks, 2008). More specifically, productivity can be improved by increasing the production techniques such as increasing greater outputs (Krishnamoorthi and Raphael, 2018) by manufacturing products off-site in more controlled conditions than which can be expected on the construction site. Higher productivities can thus be achieved by modular construction because it involves prefabricating components offsite in a factory.

Modular construction is a delivery method wherein building components are designed, prefabricated off-site in a factory and then transported to the job site for assembly to form the building. This delivery method minimizes project delays and cost overruns in the construction industry. It has the potential for reconfiguring and disassembling modules or parts of the buildings at the end-user phase to suit the user's preferences. The first step towards modular construction is in the design phase. After finalizing the drawings, construction plans are delivered to the manufacturing plant where the components will be fabricated. This process is also known as prefabrication, and it comprises the construction of building components that would be attached together to build a larger final form (Modular Building Institute, 2010).

Prefabrication is an industrial activity that takes place in a controlled environment and it has several advantages such as minimizing waste and cost, raising quality, reducing safety incidents, and most importantly, facilitating development in construction building and accelerating schedules (Legmpelos, 2013). Prefabrication components can be categorized into two broad types: non-volumetric (2D panels) and volumetric (3D units or blocks). The materials used for constructing prefabricated elements are typically steel frame, precast concrete, or timber frame panels (Schoenborn, 2012). Of these materials, timber is a desirable due to its low weight to 
strength ratio that offers structural efficiency. Using wood as a construction material is also environmentally beneficial since it is a sustainable material since engineered wood products can considerably reduce carbon dioxide emissions as wood sequesters carbon and does not emit it into the atmosphere (Steffen, 2013).

Cross-Laminated Timber (CLT) is an engineered wood product that consists of an odd number of layer of lumber that are glued together with each layer built out of dimensional lumber that is glued together. CLT has higher dimensional stability, load bearing, and thermal resistance when compared to timber framing (Gijzen, 2017). Cross laminated timber can theoretically be of any size but in practice its size is constrained by the size of the press in the manufacturing plant, limitations in transport vehicle, and construction site constraints. Prefabricated elements that are made of CLT are usually cut to fit, and wall panels are typically one or more storeys high. Window and door openings are typically cut out of the panels, without requiring additional measures such as trimmers (Krötsch \& Huß, 2018). Such a high level of prefabrication of CLT panels makes it a preferred material for use in modular construction. (Gijzen, 2017).

Due to the sustainability of operations that is associated with CLT construction, there has been a recent effort to optimize the logistics of the supply chain in order to realize cost, and time savings on projects. For instance, in the recent past, manufacturers in North America and Europe have sought to use locally available wood to manufacture CLT in order to achieve efficiency gains in the logistics of the process (Pei et al., 2016 and Gijzen, 2017). In keeping with this goal, modular construction promises to be one way to improve the productivity of CLT construction. Therefore, this paper provides a means for determining optimal strategies to be used in CLT logistics through the simulation of common processes involved with CLT construction. The first step towards simulating operations is to determine the role that the various stakeholders have and to identify an area to focus the model upon.

Figure 1a shows the stakeholders and phases of the CLT lifecycle for a typical construction project, whereas Figure 1b provides a comparison between conventional and modular processes for the stakeholders.

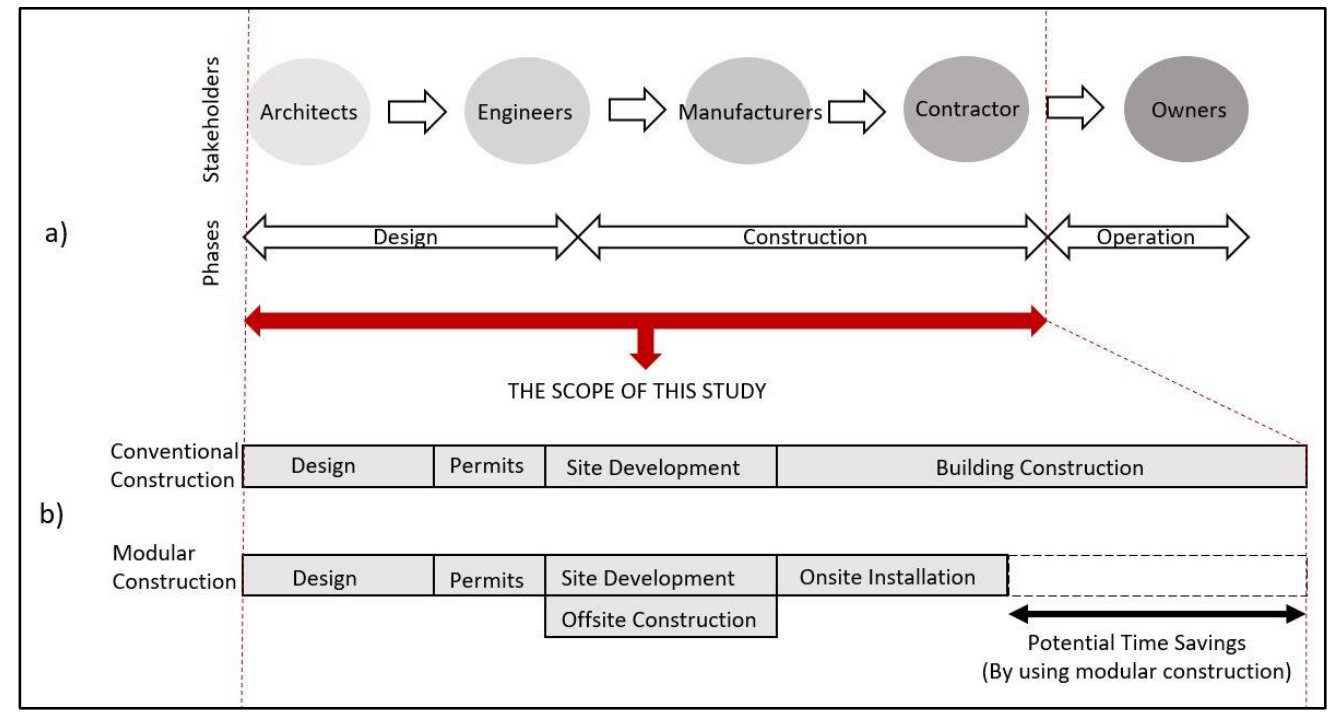

Figure 1. Modular construction vs. site-built construction considerations among stakeholders during the design and construction phases (b-Modular Building Institute, 2010) 
As shown in Figure 1-a, the stakeholders include architects and engineers in the design phase, manufacturers and contractors in the construction phase, and the owners of the building during the operational phase. This paper is focuses on the design and construction phases. Figure $1 \mathrm{~b}$ shows that modular construction enables site development to happen in parallel with offsite construction (or prefabrication) and thus enable time savings for the project. While there are several studies in modular construction, automation and industrialization as well as studies in cross-laminated timber, there is no study that investigates methods to shorten the time of construction operations for CLT modular construction from manufacturing from the factory to the site. There are still some challenges involved in the logistics and assembling them on-site. This study attempts to seek an effective method of CLT modular construction operation by using discrete event simulation to for improving productivity and reducing the duration of construction process.

\section{METHODOLOGY}

Figure 2 provides an overview of the methodology employed in this paper. The outcome of each model indicates results from the statistical data analysis.

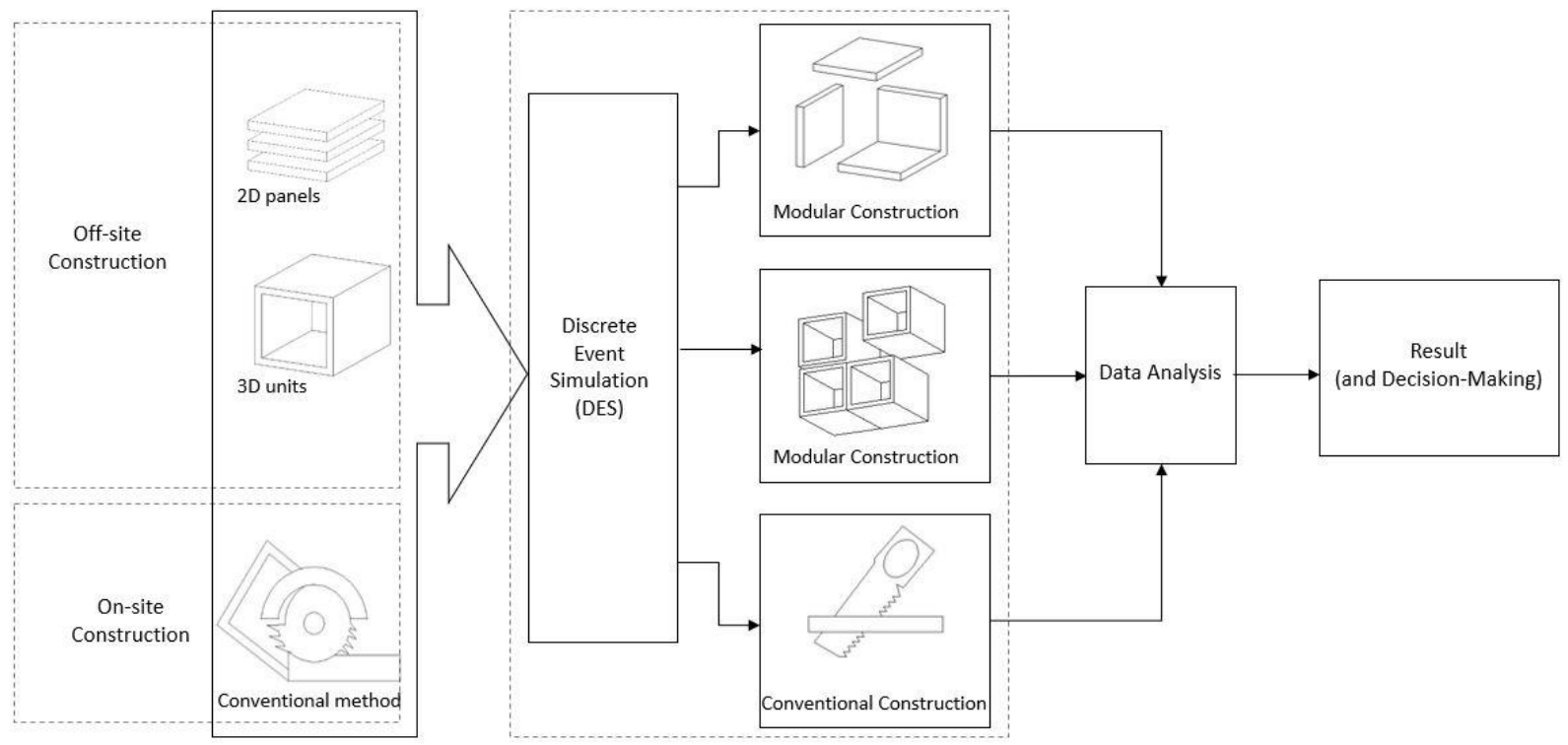

Figure 2. Comparison of construction logistics of three alternatives from factory to the job site

As seen in Figure 2, this paper provides a comparison of three alternatives: conventional building, two dimensional (2D), and 3D modular construction logistics by using discrete event simulation. Simulation is the process of modelling a real system in order to understand its performance and thus serves to compare the performance of the three systems mentioned above. Simulation is a preferred means for studying systems, especially when it is expensive or infeasible to obtain insights from the real system under study through real-world experimentations. Conducting a comparative analysis is the principal research method of this study by simulating different models to meet the best system design. Evaluating construction operations and choosing the effective alternative can be enhanced by discrete event simulation using jStrobe simulation software that implements the STROBOSCOPE language (Martinez 1996, Ionnou and Martinez, 1995). Specifically, DES is used to model CLT logistics to identify 
bottlenecks and provide sensitivity analyses of variables such as activity duration, travel times, and manufacturing plant capacity on project cost and time. A case study of conventional and modular multi-story building construction is provided to showcase the utility of the developed simulation framework.

\section{CASE STUDY}

The presented methodology is included into three categories: 1) conventional construction, that the major operation is performed on construction site and 2) CLT 2D modular construction, and 3) CLT 3D modular construction. Therefore, a hypothetical case study building has been developed in three alternatives and designed the models. Models for construction operation processes of both conventional and modular buildings are presented in this section.

\section{Conventional Construction}

Figure 3 shows a conventional construction system. Consider a truck moving from factory to the job-site. The time required by loading trucks in the factory is a uniformly distributed parameter varying between 1 and 3 hours. When the truck is fully loaded, it hauls the material to the construction site, and the duration of this activity depends on the distance between the stations. A stochastic triangular distribution is used to model the travel time of the trucks considering periods of low, median, and high durations. After unloading the truck, which takes the similar time of loading, a table saw cuts the timber on-site in a uniformly distributed form between 1.5 and 3 hours for each piece. The frames are assembled by two crews in a uniform distribution between 20 and 30 days. Some parts of the building need frames that installed by one crane. The time required to installing the frames is uniformly distributed between 2 and 3 hours.

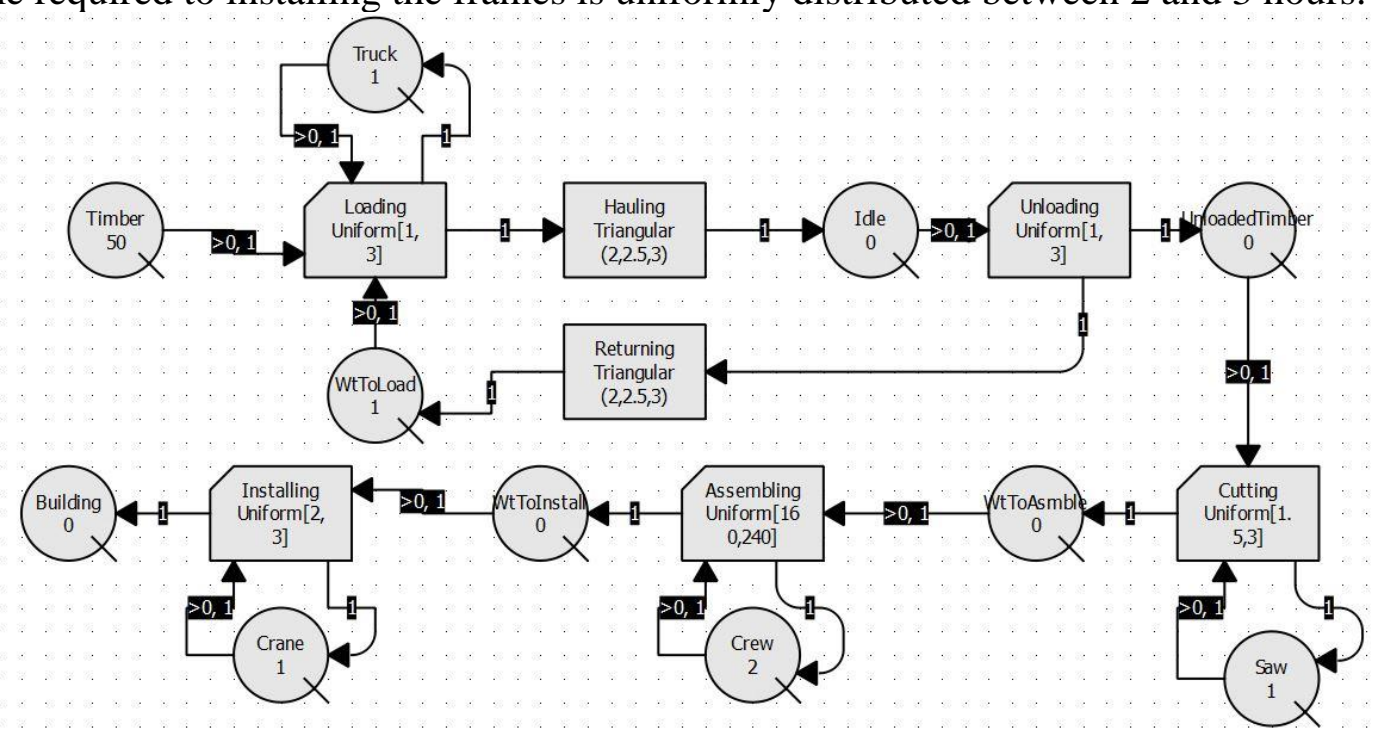

Figure 3. Simulation model for conventional construction operations

\section{Modular Construction}

In the modular building, two different models of construction operation are created; nonvolumetric and volumetric modules. Figure 4 shows the activities of assembling 2D panels onsite. CLT panels are fabricating through the manufacturing plant. The time required to make each 
panel is uniformly distributed between 30 minutes to 1 hour. After the panels are prepared, a forklift picked them up. The time required to load panels in a truck is uniformly distributed between 1 and 3 hours. Then, the truck is transported to the construction site. The time required to haul depends on the distance of the stations. However, it is usually triangular distributed between $(2,2.5,3)$ hours. After unloading the truck, which takes a similar time of loading, panels are ready to assemble. The panels assembled by a crane to create the units. The time required to make them is uniformly distributed between 10 and 20 days. Units are installed by a crane. The time required to install them is uniformly distributed between 40 days and 60 days.

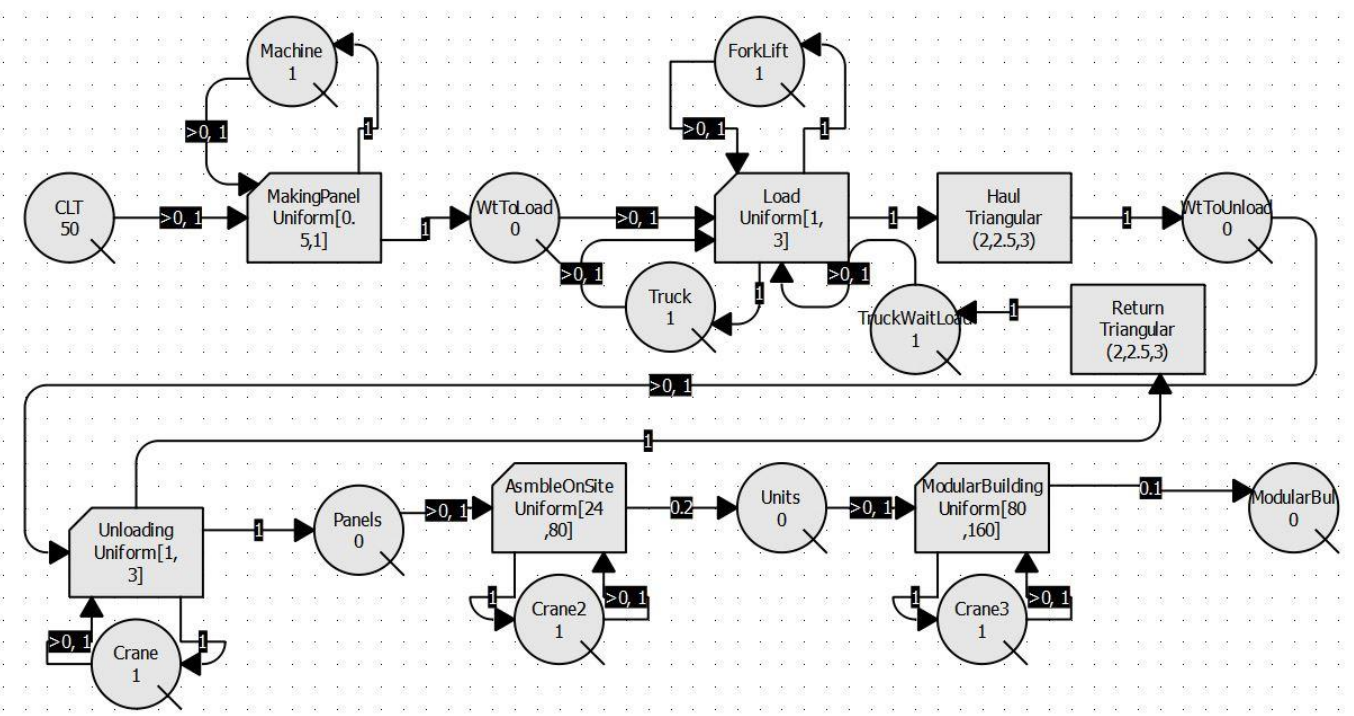

Figure 4. A simulation model of the operation process of 2D modular system, from factory to the construction site

Another model modular construction is shown in figure 5. In this model, both panels and 3D modules are constructed off-site in factories. The time required to make each panel is uniformly distributed between 30 minutes to 1 hour. Panels are assembled by a crane to make the 3D modules. The time required to make volumetric units is uniformly distributed between 5 and 10 hours. Then, the blocks are loaded by a crane. The time required to load them is uniformly distributed between 3 and 5 hours. The time required for transferring the blocks by a truck to the construction site is triangularly distributed between $(3,3.5,4)$ hours. After unloading the trucks, the modules are installed on construction site by a crane. The time required to erect the blocks is uniformly distributed between 10 and 20 days. The main difference between assembling 2D panels and 3D units is where they are, 2D panels generally are assembled on-site, while 3D panels are mostly developed through the manufacturing system. 


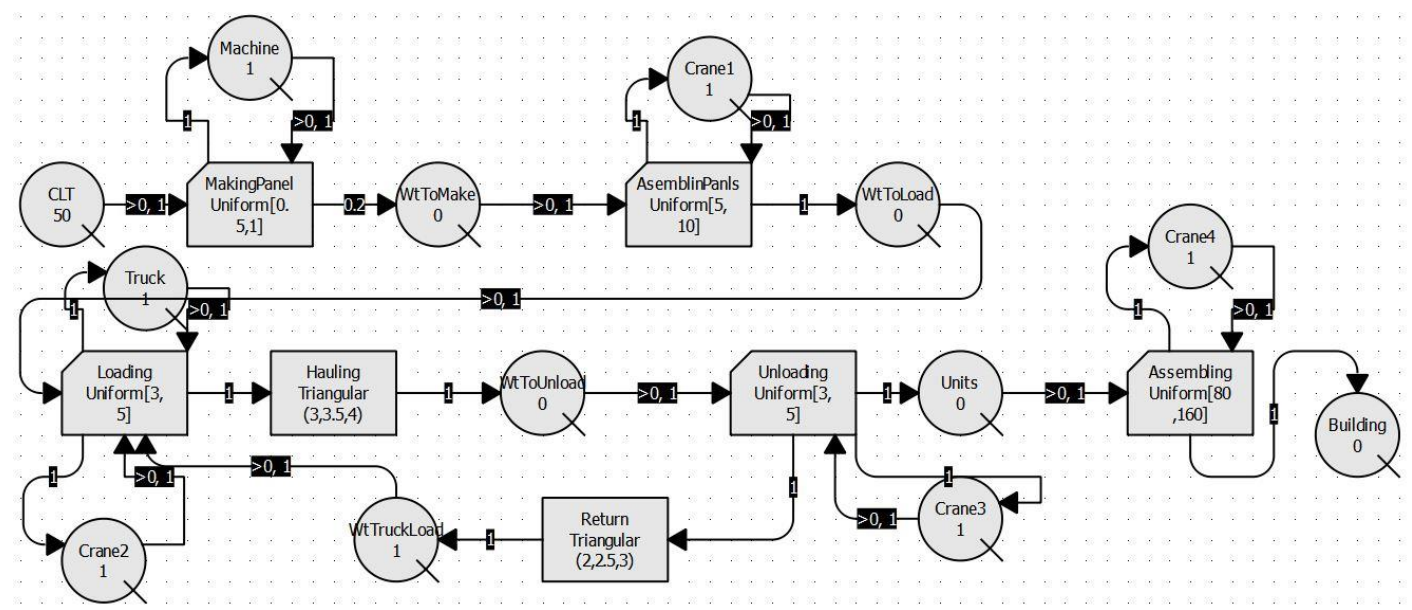

Figure 5. The model of the operation process of $3 \mathrm{D}$ unit modular construction from factory to the site

\section{RESULTS}

The comparison of output relating to time taken to complete operation of each model is shown in Table 1, that also provides the average durations for each activity.

Table 1. Comparison of activity durations for conventional, 2D, and 3D modular construction

\begin{tabular}{|c|c|c|c|c|c|}
\hline \multicolumn{2}{|c|}{ Conventional Construction } & \multicolumn{2}{|c|}{ 2D Modular Construction } & \multicolumn{2}{|c|}{ 3D Modular Construction } \\
\hline Activity & $\begin{array}{l}\text { Ave. } \\
\text { Duration }\end{array}$ & Activity & $\begin{array}{l}\text { Ave. } \\
\text { Duration }\end{array}$ & Activity & $\begin{array}{l}\text { Ave. } \\
\text { Duration }\end{array}$ \\
\hline Loading & 2.1 & MakingPanel & 0.75 & MakingPanel & 0.75 \\
\hline Hauling & 2.43 & Loading & 2.17 & AssemblingPanels & 7.9 \\
\hline Unloading & 1.88 & Hauling & 2.44 & Loading & 4.16 \\
\hline Returning & 2.5 & Unloading & 2.08 & Hauling & 3.47 \\
\hline Cutting & 2.23 & Returning & 2.46 & Unloading & 3.79 \\
\hline Assembling & 201.3 & AsmblingOnSite & 48.06 & Returning & 2.44 \\
\hline \multirow[t]{2}{*}{ Installing } & 2.46 & ModularBuidling & 124.83 & AssemblingOnSite & 124.07 \\
\hline & 214.95 & & 182.79 & & 146.58 \\
\hline \multicolumn{2}{|c|}{ Total Average Duration } & \multicolumn{2}{|c|}{ Total Average Duration } & \multicolumn{2}{|c|}{ Total Average Duration } \\
\hline
\end{tabular}

It is clearly showed that there is a considerable difference between conventional and modular construction activity duration. The total average duration in conventional construction is greater than modular construction, because activities such as cutting and assembling on-site takes more time. Furthermore, the total average duration in $2 \mathrm{D}$ modular construction is more than the $3 \mathrm{D}$ modular construction.

\section{CONCLUSION}

Modular construction using CLT is a new method for building that could help stakeholders improve productivity and save time on projects. The principal objective of this study is to 
develop an approach for comparing productivity between three alternatives which have the minimum cost and time. Conventional, CLT 2D and 3D modular construction logistics are designed and simulated through $\mathrm{jStrobe}$, a discrete event simulation system. Simulation run released statistical data. Results show that the total average activity duration and total cost of CLT modular construction is lower than the conventional building. Comparing the total average activity duration of CLT 2D and 3D modular construction presented that the 2D modular construction requires less time. Although the activity duration of $3 \mathrm{D}$ modular construction is less than 3D modular construction, its estimated cost is greater. The key findings summarized that if the stakeholders are seeking for a shortest period of construction, they can select the CLT 3D modular building. But if they are looking for the reduced price, with a considerable time saving, the can choose the 2D modular construction. Future research will seek to apply this methodology to a real-world case study operation to validate the results of this simulation.

\section{REFERENCES}

Blind, K. (2013). The impact of Standardization and Standards on Innovation. Manchester Institute of Innovation Research. Retrieved from: http://www.innovationpolicy.org.uk/share/14_The\%20Impact\%20of\%20Standardization\%20and\%20Standards\% 20on\%20Innovation.pdf

Eastman, C. M., and Sacks, R. (2008). "Relative productivity in the AEC industries in the United States for on-site and off-site activities." Journal of construction engineering and management, 134(7), 517-526.

Gijzen, R. (2017). "Modular cross-laminated timber buildings." Delft University of Technology.

Ioannou, P. G., and Martinez, J. C. (1996). "Comparison of construction alternatives using matched simulation experiments." Journal of construction engineering and management, 122(3), 231-241.

Ioannou, P. G., and Martinez, J. (1995). "Evaluation of Alternative Construction Process Using Simulation." Proceedings, Construction Congress, ASCE, San Diego, California.

Krishnamoorthi, S., and Raphael, B. (2018). "A methodology for analysing productivity in automated modular construction." Berlin, Germany.

Krötsch, S., Huß, W. (2018). Structural components and elements. In "Manual of Multi-Storey Timber Construction” Kaufmann, H., Krötsch, S., Winter, S. (eds). Edition Detail, pp: 5069

Legmpelos, N. (2013). “On-site Construction Versus Prefabrication.” Massachusetts Institute of Technology.

Modular Building Institute. (2010). Improving Construction Efficiency \& Productivity with Modular Construction.

Pei, S., Rammer, D., Popovski, M., Williamson, T., Line, P., and Lindt, J. W. van de. (2016). “An Overview of CLT Research and Implementation in North America." Vienna, Austria.

Schoenborn, J. M. (2012). "A Case Study Approach to Identifying the Constraints and Barriers to Design Innovation for Modular Construction." Virginia Polytechnic Institute and State University.

Steffen, L. (2013). "Low carbon construction systems using prefabricated engineered solid wood panels for urban infill to significantly reduce greenhouse gas emissions." Sustainable Cities and Society, 6, 57-67. 